\title{
Super ThinkWash: Um Jogo Digital Educacional inspirado na vida real para desenvolvimento do Pensamento Computacional em crianças
}

\author{
Taynara Cerigueli Dutra ${ }^{1}$, Daniel Felipe ${ }^{1}$, Isabela Gasparini ${ }^{1}$, Eleandro Maschio ${ }^{2}$ \\ ${ }^{1}$ Universidade do Estado de Santa Catarina (UDESC) Joinville - SC - Brasil \\ ${ }^{2}$ Universidade Tecnológica Federal do Paraná (UTFPR) Guarapuava - PR - Brasil \\ taynara.dutra27@gmail.com, danielfeelipe012@gmail.com
isabela.gasparini@udesc.br, eleandromeutfpr.edu.br
}

\begin{abstract}
This article presents the development of an educational digital game titled "Super ThinkWash". The game aims to help children at the beginning of the literacy process to develop Computational Thinking skills and work on basic math concepts. Also, to explore the interdisciplinarity of Computational Thinking with activities of practical life, the game has as its theme the laundry process, and each phase represents one of the necessary activities. The evaluation of the game was performed by Computer Science students, and as a result, positive feedbacks were obtained about the design and available features. Finally, the game is in its first functional version consisting of 3 phases.
\end{abstract}

\begin{abstract}
Resumo. Este artigo apresenta o desenvolvimento de um jogo digital educacional intitulado "Super ThinkWash". O jogo tem como objetivo auxiliar crianças no início do processo de alfabetização a desenvolver habilidades do Pensamento Computacional e trabalhar conceitos básicos da Matemática. Também, de maneira a explorar a interdisciplinaridade do Pensamento Computacional com atividades da vida diária, o jogo tem como temática o processo de lavagem de roupa. A avaliação do jogo foi realizada por estudantes de Ciência da Computação e como resultados obtiveram-se feedbacks positivos sobre o design e as funcionalidades disponíveis. Por fim, o jogo encontra-se em sua primeira versão funcional e é constituído de 3 fases.
\end{abstract}

\section{Introdução}

A educação brasileira, em seu contexto geral, apresenta um processo de ensino baseado em técnicas tradicionais, em que os estudantes aprendem maneira passiva e não são instigados a desenvolver habilidades imprescindíveis para o século XXI e para o presente contexto tecnológico da sociedade. Dessa forma, constata-se que esses métodos de ensino têm se mostrado pouco efetivos para os estudantes atuais [Cavadas et al. 2019].

Com o intuito de contrapor esse cenário e possibilitar aos estudantes uma aprendizagem significativa e o desenvolvimento de habilidades, há inúmeros movimentos e estudos para a integração do ensino da Computação à Educação Básica. Uma das vertentes desse ensino é o Pensamento Computacional (PC). O PC é considerado uma forma distinta de pensar com base em conceitos da Ciência da Computação, que provê a solução 
de problemas, o desenvolvimento de sistemas e a compreensão do comportamento do ser humano [Wing 2006]. O desenvolvimento do PC auxilia na estruturação do raciocínio com foco na formulação e resolução de problemas e proporciona inúmeros benefícios à capacidade de raciocinar dos estudantes, bem como, na sua formação como um todo [Koscianski e Glitz 2017]. Também, o PC é uma habilidade intelectual básica a ser adquirida por todos os indivíduos, como a leitura, a escrita e a aritmética [Wing 2006].

O PC pode ser desenvolvido por intermédio de abordagens plugadas, em que há a utilização de dispositivos tecnológicos e desplugadas, em que se utiliza de materiais concretos. No que tange à abordagem plugada, uma das possibilidades é o uso de jogos digitais educacionais (JDE). Tais jogos estimulam o raciocínio lógico e o processo de resolução de problemas dos estudantes, por meio de cenários lúdicos e dinâmicos. Desta forma, eles promovem um ambiente motivador e divertido, para o qual o estudante necessita destinar sua atenção na busca pela melhor estratégia para a solução do problema em que se encontra.

Além disso, o PC pode promover a interdisciplinaridade entre as diversas áreas do conhecimento, permitindo a associação da tecnologia com os conteúdos das disciplinas regulares, e também de diversos segmentos como a saúde, autocuidado, mercado de trabalho e situações cotidianas. Portanto, as habilidades provenientes do desenvolvimento do pensar computacionalmente podem auxiliar as pessoas nas mais diversas áreas de suas vidas. Com base nesse contexto, o presente trabalho objetiva apresentar um JDE desenvolvido, registrando o seu processo de criação e avaliação realizada. Este jogo foi intitulado de Super ThinkWash, projetado para plataforma desktop e desenvolvido para crianças a partir dos 6 anos. O jogo associa as habilidades do $\mathrm{PC}$ a conceitos matemáticos iniciais aplicados a situações do dia a dia, como o processo de lavagem de roupas.

O artigo está estruturado como segue. A Seção 2 aborda os conceitos fundamentais que servem como base teórica para o entendimento dos temas discutidos. A Seção 3 apresenta os trabalhos relacionados. A Seção 4 detalha o processo de desenvolvimento do jogo. Na Seção 5, são descritas as características do jogo. Em seguida, a Seção 6, relata os testes do jogo e como eles foram realizados. Por fim, A Seção 7 abrange as considerações finais e os trabalhos futuros.

\section{Fundamentação teórica}

O Pensamento Computacional é caracterizado como os processos de pensamento envolvidos na formulação de um problema e na expressão de sua solução, de maneira que possam ser realizadas por um computador ou um humano com eficácia. É uma forma distinta de pensar com base em conceitos da Ciência da Computação [Wing 2011].

Também é considerado a capacidade criativa, crítica e estratégica do ser humano de empregar os fundamentos da Computação em diversas áreas do conhecimento, com o objetivo de identificar e resolver problemas colaborativamente, por meio de uma sequência de passos definidos que possibilite a execução por uma pessoa ou uma máquina. Pensar computacionalmente desenvolve habilidades cognitivas necessárias para utilizar a Computação na resolução de problemas complexos. Quatro pilares constituem o PC, sendo a decomposição, o reconhecimento de padrões, a abstração e o algoritmo [Brackmann 2017].

O pilar de decomposição concerne ao processo em que os problemas são separados 
em partes para serem melhores compreendidos. Após a decomposição de um problema, o pilar de reconhecimento de padrões pode ser empregado para deliberar os padrões entre os subproblemas gerados ou entre problemas já solucionados. Trata-se da abstração de um problema, a identificação do que é relevante para a solução e o descarte de particularidades irrelevantes, realizando a filtragem dos dados e sua classificação. Por fim, o pilar de algoritmo refere-se à definição de uma sequência de passos para realização de uma tarefa [Brackmann 2017].

Por abranger métodos para a solução de problemas com base em conceitos e técnicas da Computação, o PC pode auxiliar no desenvolvimento do raciocínio lógico de estudantes do ensino básico, já que muitos apresentam dificuldades de estruturar seu pensamento de forma lógica objetivando a resolução de problemas. Pensar computacionalmente aprimora e reforça habilidades intelectuais e, por isso, proporciona inúmeros benefícios educacionais - além de que, pode ser aplicado a qualquer domínio [Wing 2011]. Com o PC, os estudantes aprendem técnicas como abstração, organização e sequência de instruções para a resolução dos problemas, que os auxiliará na estruturação da sua forma de pensar [Koscianski e Glitz 2017].

As novas abordagens de ensino visam integrar o uso de ferramentas digitais que, por já estarem incorporadas à vida diária dos atuais estudantes, diminuem a curva de aprendizagem [von Wangenheim e von Wangenheim 2012]. Nesse contexto, os jogos são apontados como ferramentas capazes de oferecer uma aprendizagem relevante pela inerência divertida de suas estruturas e sua capacidade de promover engajamento [Gee 2003].

Em relação aos JDE, tratam-se de recursos tecnológicos relevantes ao serem empregados como ferramenta metodológica no apoio ao professor em sua prática educativa. Além disso, proporcionam o ensino dos conteúdos de disciplinas regulares de modo lúdico e prazeroso, o que resulta em práticas educacionais atrativas, dinâmicas e motivadoras [Savi e Ulbricht 2008]. O jogo educacional, utilizado em sala de aula, desvirtua da ideia de apenas levar entretenimento, pois prioriza a aprendizagem de conteúdos e o desenvolvimento de novas competências.

Ademais, os jogos proporcionam um ambiente que permite o aprendizado pela experimentação e pela descoberta, aprendendo na prática e recebendo feedbacks constantes e instantâneos com base em suas ações durante o jogo. Isso proporciona ao estudante um papel ativo no seu processo de aprendizagem. Ao jogar, o estudante se afasta da passividade e transfere o pensamento em uma situação-desafio que dispõe de diversas ferramentas com as quais deve solucionar o problema proposto. Dessa maneira, há a necessidade de produzir novas associações cognitivas com o objetivo de encontrar a solução e posteriormente, construir o conhecimento [Santos 2006].

\section{Trabalhos relacionados}

Diferentes estudos têm sido conduzidos visando à aplicação de diversas ferramentas para o desenvolvimento do PC na Educação Básica. Nesse contexto, o trabalho de Gomes et al. (2015), relata a avaliação de um jogo educacional chamado The Foos. Este jogo apresenta conceitos de Ciência da Computação e programação, é inspirado em linguagens de programação visual como Scratch, e utiliza-se da combinação de quebra-cabeças desafiadores e brincadeiras criativas. O jogo objetiva auxiliar na disseminação do PC para crianças a partir dos cinco anos. Ele foi avaliado de maneira objetiva por especialistas 
e de modo formativo pelo público-alvo em duas escolas (com a utilização computadores e de tablets no ambiente domiciliar). Como resultado, destaca-se a motivação dos estudantes, que demonstraram um engajamento intenso com o jogo, mesmo diante de desafios para os quais não conseguiram estabelecer a solução de imediato. De forma geral, observou-se que as crianças apresentaram maiores dificuldades nas fases mais complexas e no entendimento da lógica associada aos blocos [Gomes et al. 2015].

O trabalho de Lima et al. (2010) apresenta um jogo educacional chamado Gramágica e demonstra o viés interdisciplinar do PC, ao aliá-lo ao ensino de conceitos pertinentes a língua portuguesa. O jogo é de ação e aventura em plataforma, com o tema de fantasia e puzzles. Gramágica se baseia nos pilares do PC e tem como objetivo promovêlo por meio do raciocínio lógico na resolução de problemas sobre classificação silábica. O público-alvo são crianças a partir de 6 anos. O progresso da aprendizagem sobre a classificação das palavras está relacionado à jornada da heroína que deve chegar até a torre mais alta. O jogo possui seis fases, sendo que a dificuldade aumenta a cada fase, sem sobrecarga de informações. A avaliação ocorreu com três desenvolvedores de jogos e considerou a usabilidade diante das heurísticas de Nielsen (1994).

Outro jogo que pratica a interdisciplinaridade é o JDE Tricô Numérico, apresentado por David et al. (2018). Esse jogo possui o estilo ação/aventura e narra a história de Saara, herdeira de uma antiga família especialista em tricô. O jogo tem como propósito promover a aprendizagem Matemática aliada ao desenvolvimento do PC e seus pilares por meio da resolução de problemas matemáticos. Para a avaliação do jogo, considerou-se a experiência do usuário utilizando-se do teste GameFlow. Após a coleta de dados e análise de resultados dos testes de imersão e diversão (GameFlow), o jogo foi classificado por 93,3\% dos usuários como desafiador e o critério com menor aprovação foi o feedback, que teve $56,6 \%$ dos votos. No teste de análise do conhecimento (EGameFlow), $95 \%$ dos entrevistados afirmaram que o jogo promoveu a aprendizagem do conteúdo proposto.

Com base em análises, constatou-se que alguns dos trabalhos relacionados afirmam exercitar os pilares do PC, porém não apresentam como estão empregados, como é o caso do jogo de David et al. (2018). Outra questão observada é que muitos trabalhos disponíveis na literatura abordam o PC unicamente no contexto da programação, ou seja, para a criação de algoritmos, como, por exemplo, o jogo The Foos [Gomes et al. 2015]. Também, muitas das atividades propostas em jogos direcionados ao desenvolvimento do PC prezam pela interdisciplinaridade com conteúdos de disciplinas regulares. Assim, opondo-se a esse cenário, o presente trabalho tem como intuito auxiliar no desenvolvimento do PC em crianças, empregando como temática atividades da vida cotidiana, inicialmente com foco no processo de lavagem de roupa, tornando assim, as tarefas do jogo relevantes e significativas para a vida real do estudante.

\section{Processo de desenvolvimento}

O processo de desenvolvimento foi iniciado com a idealização do jogo, empregando os conceitos trazidos por uma pesquisa bibliográfica desempenhada a respeito dos principais temas abordados. Com base nisso, por meio de sessões de brainstorming, ideias foram estabelecidas, discutidas e avaliadas junto à equipe do projeto, constituída de dois pesquisadores seniores, um especialista em PC e outro em IHC, uma aluna mestranda e um aluno de graduação, sendo todos da área de Computação. Foram realizadas também reu- 
niões com uma profissional terapeuta ocupacional, que auxiliou na tomada de decisões importantes para o JDE. Cada especialista propôs contribuições referentes ao seu tema de estudo, como a aplicação dos pilares do PC e das habilidades cognitivas relacionadas, interface e interação do jogo, e as funções cognitivas de crianças.

Sobre a tecnologia empregada para desenvolvimento do jogo, utilizou-se como game engine a plataforma Unity, por possuir licença livre para jogos sem fins lucrativos e fornecer suporte para linguagem de programação C\#. Outra motivação foi a possibilidade de criação de cenas, ambientes e elementos, tanto visuais como sonoros, e funcionalidades úteis, como arrastar e soltar. Além disso, o jogo desenvolvido pode ser executado em diversos sistemas operacionais, incluindo Windows, macOS e Linux.

A Figura 1 apresenta as etapas para desenvolvimento e avaliação do jogo, que são descritas nas próximas seções.

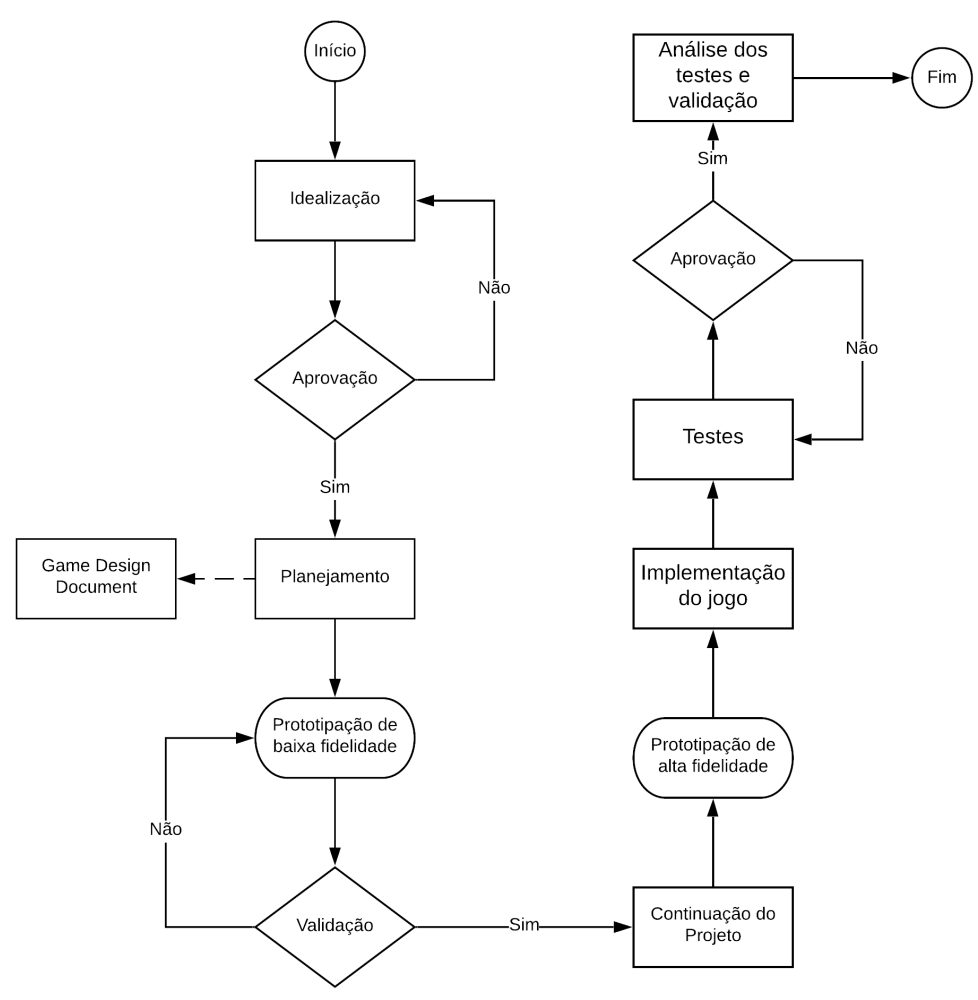

Figura 1. Diagrama ciclo de desenvolvimento do jogo

\subsection{Idealização e levantamento de requisitos}

Nesta primeira etapa, definiu-se a motivação do jogo, o contexto, o público-alvo e as tecnologia envolvidas. Como o objetivo do jogo educacional era abordar atividades da vida diária, estabeleceu-se como temática o processo de lavagem de roupa, contextualizando a possibilidade do PC ser inserido às atividades cotidianas, como lavar e guardar roupas, limpar a casa e cozinhar. Outro fator é que, utilizando-se de tarefas comuns, os jogadores possam realizar associações com as suas próprias vivências.

Os requisitos para o presente trabalho foram elencados no início do processo de desenvolvimento e são a base para a interface e as funcionalidades do jogo. Com base no 
modelo de Grimes e Hounsell (2019), os requisitos foram classificados em: obrigatórios, aqueles que o jogo deve contemplar; desejáveis, aqueles que o jogo pode contemplar; e restrições, aqueles que o jogo não deve oferecer.

Os requisitos de um JDE vão além dos requisitos técnicos, pois ao contrário de outros sistemas de interação, ou mesmo de jogos de entretenimento, ao desenvolver jogos educacionais, requisitos relacionados à aprendizagem precisam ser identificados e estabelecidos [Henrique 2016]. Portanto, os requisitos de aprendizagem definidos para o jogo, relacionam-se aos pilares do $\mathrm{PC}$, sendo internamente trabalhados com os jogadores à medida que realizam as tarefas para a lavagem de roupas e avançam de fase. Todos os pilares são abordados: reconhecimento de padrões, abstração, decomposição e algoritmos. Por intermédio do PC, o estudante também poderá desenvolver habilidades, como o raciocínio lógico e crítico, a resolução de problemas, a capacidade de abstração, entre outros. Também se determinou a utilização de conceitos básicos matemáticos, assim permitindo a interdisciplinaridade do PC com a Matemática, conforme defendido pela BNCC (2018).

\subsection{Planejamento e documentação}

Após a definição dos requisitos, iniciou-se o planejamento definindo-se o Game Design (GD) do jogo e posterior a documentação das decisões realizadas nesta etapa. O GD é a fase do processo de desenvolvimento que visa estabelecer como o jogo deve ser [Schell 2010]. Nessa fase, deve-se determinar todos os detalhes referentes a como o jogo será jogado. Com a finalidade de formalizar e documentar as decisões referentes ao jogo durante a fase de GD, um documento, chamado Game Design Document (GDD), é elaborado.

No GDD deve ser descrito todo o processo do desenvolvimento do jogo, gerenciando as informações a respeito da classificação, da história, da jornada do personagem, dos elementos de diversão e de interação, das mecânicas, do gameplay, do cenário, do público-alvo e de outras informações necessárias do jogo [Lima et al. 2019]. Assim, para definição do GDD do presente jogo, os elementos descritos fundamentaram-se em Fisher (2014).

\subsection{Prototipação de baixa e alta fidelidade}

$\mathrm{Na}$ etapa seguinte, realizou-se a prototipação de baixa fidelidade por meio de telas e figuras estáticas para representação dos personagens e do cenário, além do funcionamento de cada fase. Com a prototipação foi possível realizar ajustes nas definições iniciais e atualizar o GDD, validar o projeto e dar início a implementação do jogo.

Os primeiros itens desenvolvido foi a tela inicial e os cenários de cada fase. Para que, prioritariamente, os mecanismos do jogo fossem concluídos, utilizou-se das imagens da prototipação de baixa fidelidade, depois alteradas para constituírem a versão de alta fidelidade do jogo.

\section{Super ThinkWash: O jogo}

O JDE criado tem como intuito auxiliar no desenvolvimento do PC para estudantes do Ensino Fundamental I. O jogo foi denominado "Super ThinkWash", inspirado em títulos de jogos clássicos como, por exemplo, Super Mario 64 e Super Bomberman. A segunda parte do nome associa o pensar, do PC, com o tema do jogo, que é o processo de lavagem de roupa. O jogo tem como público-alvo crianças de 6 a 10 anos. 


\subsection{Narrativa}

O jogo apresenta o processo de lavagem de roupas e as tarefas que o constituem, sendo elas: separar as peças de roupa por categorias e adicioná-las em seus devidos cestos (limpas e sujas), colocar as roupas sujas na máquina de lavar, incluir o sabão e em seguida, ligar a máquina. Por fim, as peças de roupas devem ser guardadas nas suas respectivas gavetas, observando a quantidade limitante. Ao realizar tais atividades, que no jogo estão subdivididas em fases, o estudante intrinsecamente necessita estruturar o seu pensamento para reconhecer os problemas, identificar os padrões de cada atividade, decompor em estratégias e definir uma sequência de passos para a resolução. Assim, os pilares do PC são colocados em prática. A Figura 2 apresenta algumas das telas do jogo, sendo respectivamente a tela inicial, a tela de menu, a escolha de personagens e uma das telas de instruções fornecidas.

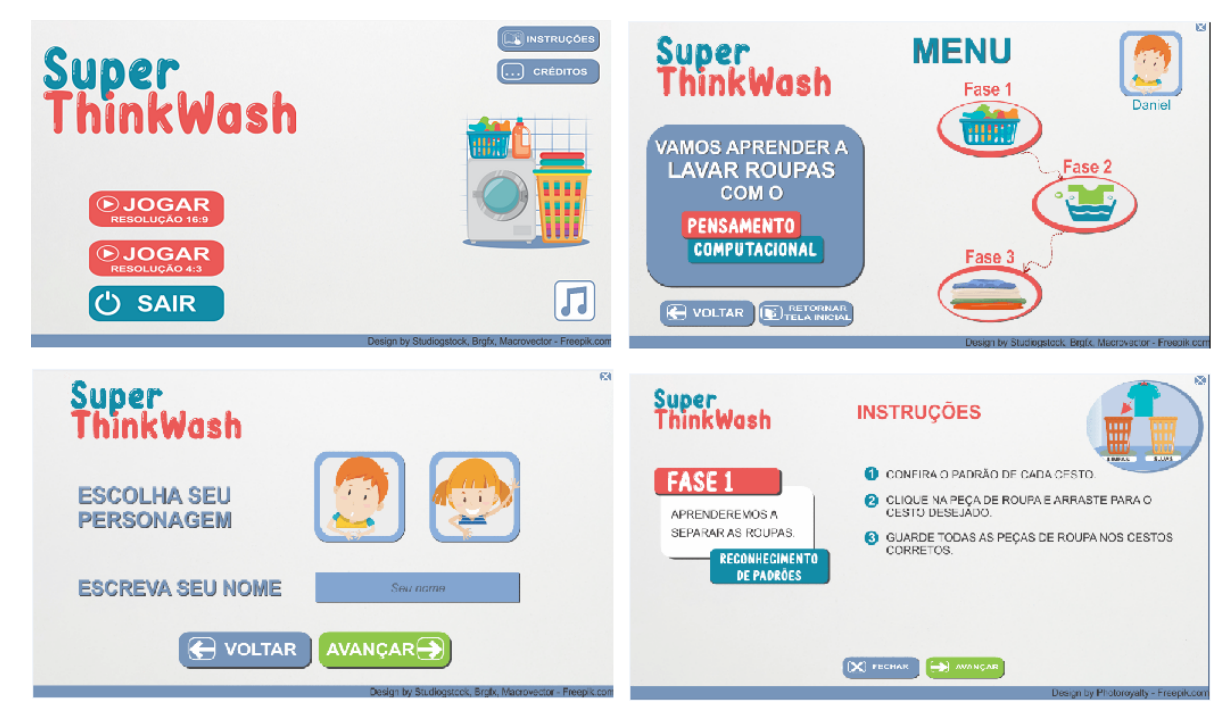

Figura 2. Telas do jogo Super ThinkWash

\subsection{Fases e níveis}

O jogo Super ThinkWash é composto por 3 fases, cada qual é constituída de três níveis: fácil, médio e difícil. A implementação atual dispõe do nível fácil nas três fases. Durante as fases e níveis, os pilares do PC são abordados nas tarefas que compõem o processo de lavagem de roupas, em que cada fase trata de uma das tarefas necessárias e um dos pilares de forma primária, não excluindo a necessidade dos demais pilares para a realização da atividade.

A fase 1 utiliza o Reconhecimento de Padrões como pilar primário. Nela, o jogador precisa categorizar as peças espalhadas no cenário e adicioná-las ao cesto correto, separando-as em roupas sujas e limpas. A Fase 2 trabalha o pilar Algoritmos e o jogador tem como objetivo adicionar todas as peças sujas do cesto de roupas à máquina de lavar, em seguida adicionar sabão e ligar a máquina, estabelecendo assim, uma sequência de passos a serem seguidos. Por último, na Fase 3, o jogador aplica, como pilares primários, a Decomposição e Abstração, com o intuito de guardar as peças de roupa nas devidas gavetas, respeitando a capacidade de cada uma e o valor (tamanho) atribuído a cada roupa. Na Figura 3 podem ser visualizadas as respectivas fases descritas. 


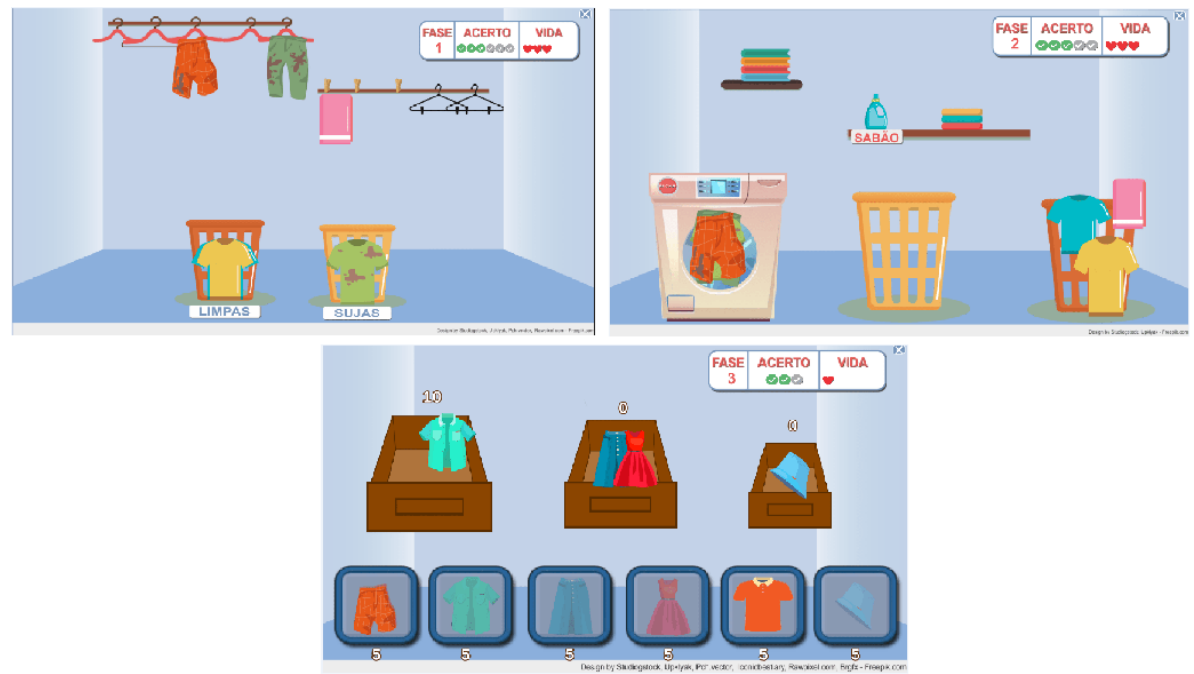

Figura 3. Fases do jogo Super ThinkWash

\subsection{Mecânicas}

Um dos elementos mais importantes de um jogo é a sua mecânica, que consiste nas regras que definem o funcionamento e proporciona a jogabilidade. No jogo Super ThinkWash, destaca-se o mecanismo de drag-and-drop, em que o jogador clica sobre o objeto informado, arrasta e solta no local correto, conforme a ação indicada pelo próprio jogo. Esse mecanismo foi implementado de modo a não permitir que o jogador possa despejar o objeto em qualquer parte do cenário, sendo possível somente nos lugares propícios. Como exemplo, na Fase 1, caso o jogador clique e arraste uma peça de roupa até o cesto incorreto, a ação torna-se incompleta e o item que corresponde à peça de roupa retorna para a sua área de origem.

\subsection{Feedbacks}

Outro elemento importante dos jogos educacionais são os feedbacks construtivos e imediatos, que auxiliam o jogador na realização das tarefas e guiam o desempenho e a performance dele, ao longo do jogo. Os feedbacks do jogo Super ThinkWash, auxiliam o jogador na realização das tarefas e possibilitam que ele obtenha um respaldo com base nas ações executadas. Os feedbacks são tanto visuais quanto auditivos.

Ao realizar as tarefas, o jogador acumulará acertos quando as ações estiverem certas, e perderá vidas ao realizar ações não permitidas. Essas informações são apresentas no painel disposto no canto superior direito do jogo. Ao perder todas as vidas, a fase é encerrada e um novo feedback é apresentado. Quando o jogador completa todas as ações corretas, vencerá a fase e um feedback será informado, incentivando-o a progredir para a próxima fase. Ao passar por todas as fases, o jogador é parabenizado por vencer o jogo. Os feedbacks finais de fase podem ser visualizados na Figura 4.

\subsection{Design visual}

Com vistas ao design do jogo, objetivou-se proporcionar um ambiente atrativo e lúdico às crianças, além de representar o contexto do jogo, focado no processo de lavagem de roupas. Para tal, utilizaram-se elementos com temática infantil e cenários que remetem 


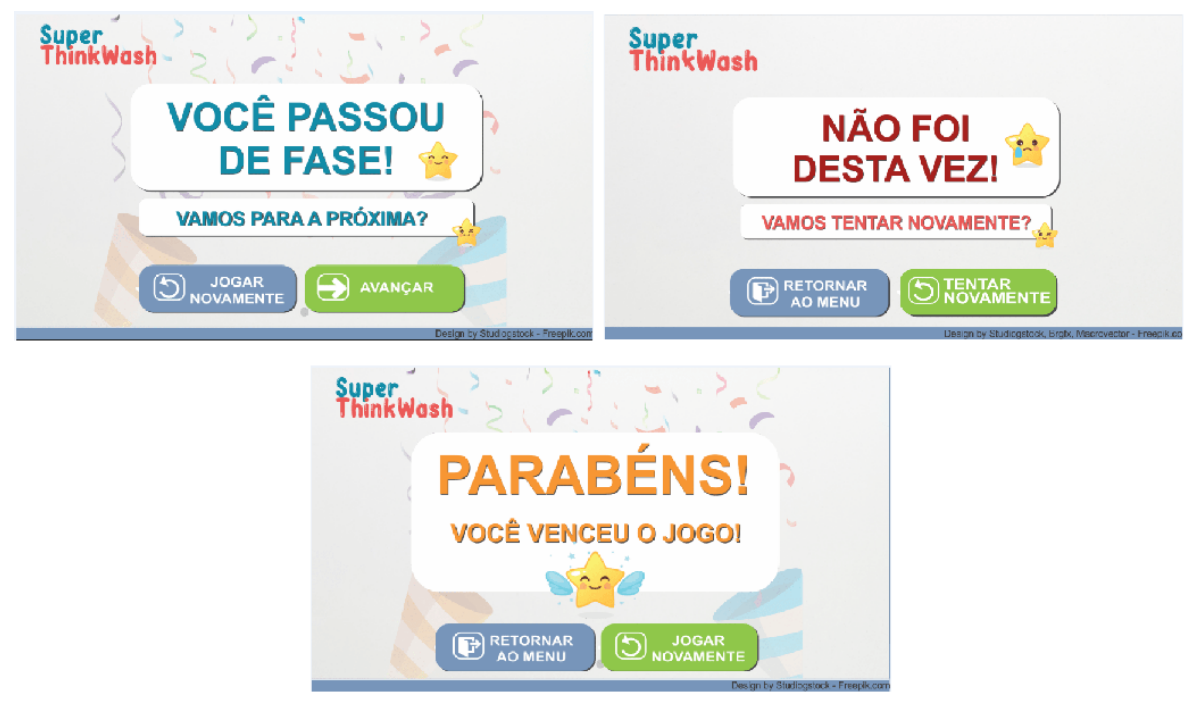

Figura 4. Feedbacks final de fases

ao ambiente de uma casa, como exemplo: lavanderia, cabides, cestos, entre outros. Sobre as cores utilizadas, definiu-se uma paleta de cores limitada, com um contraste agradável, mantendo um padrão harmônico. Também, priorizando uma navegação e experiência aprimoradas e menos cansativa para aos jogadores, com base nas heurísticas de Nielsen (1994), estabeleceu-se uma interface com poucos elementos, contemplando frases e conceitos que sejam familiares às crianças. Além de que, com fundamento na heurística "consistência e padrões" de Nielsen, mantiveram-se padrões e a mesma organização visual para os botões e telas ao longo do jogo.

\section{Avaliação}

A avaliação do jogo foi realizada por três estudantes do curso de Ciência da Computação, que não pertencem à equipe de desenvolvimento, e com conhecimentos da área de Interação Humano-Computador (IHC) - pois assim, conseguiriam reconhecer os problemas de interação do jogo. Os estudantes receberam um protocolo de teste, com instruções para a realização das atividades requeridas pelo jogo. Devido à pandemia de COVID-19, os testes foram realizados por cada estudante de forma individualizada e remota, de modo que não houve o monitoramento. Para tal, tanto o jogo quanto o protocolo de teste foram enviados para cada avaliador. Após terem utilizado o jogo, os avaliadores foram convidados a responderem um questionário, disponível on-line.

Essa avaliação teve como intuito colocar o avaliador na posição de público-alvo e verificar as suas concepções, dificuldades e erros encontrados ao utilizar o jogo. O questionário era composto por 12 perguntas, que objetivavam conhecer o perfil do avaliador, além de suas percepções ao avaliar cada tela e funcionalidade do jogo.

Com base nas respostas obtidas, constatou-se que aperfeiçoamentos precisavam ser realizados para aprimorar o design do jogo, em relação à padronização dos botões e posição de elementos. Também, os avaliadores apresentaram sugestões quanto ao formato do jogo dependendo do monitor utilizado (i.e., relacionado à resolução de tela), às instruções oferecidas para as fases, além de detalhes relacionados a elementos da interface presentes em cada fase. Tais recomendações foram atendidas e os problemas encontra- 
dos resolvidos. Dessa forma, as telas e funcionalidades apresentadas neste artigo já são versões atualizadas do jogo, com base na avaliação.

Quanto aos pontos positivos destacados pelos avaliadores, elencou-se que o jogo é uma maneira diferente e criativa de trabalhar o PC, além de ensinar boas práticas do dia a dia de forma divertida e interativa. Em relação ao design, foi observado uma boa disposição dos elementos, facilitando a navegação por entre as telas. Além disso, relatou-se que os elementos gráficos são atrativos e apresentam boa resolução. No que diz respeito ao som do jogo, foi comentado ser agradável e atrair a atenção do jogador, além de proporcionar feedback sonoro.

\section{Considerações finais e trabalhos futuros}

Os JDE se apresentam como uma ferramenta para trabalhar de maneira divertida e dinâmica o PC junto às crianças. Ademais, são considerados uma ferramenta metodológica engajadora, motivante e lúdica, capaz de aliar o ensino de conteúdos com o entretenimento. Com vistas a esse cenário, desenvolveu-se o jogo Super ThinkWash, detalhado neste artigo, cujo objetivo é auxiliar no desenvolvimento do PC em crianças do Ensino Fundamental I. O jogo visa aliar as habilidades do PC de modo interdisciplinar a atividades cotidianas e a conceitos matemáticos básicos, empregando um cenário lúdico para atrair e motivar estudantes na utilização dessa ferramenta como meio instrucional.

O jogo é constituído de três fases e três níveis que se referem às atividades que compõem o processo de lavagem de roupa. Cada fase tem o intuito de trabalhar de forma primária com um dos pilares do $\mathrm{PC}$, possibilitando que crianças possam desenvolver a capacidade de resolução de problemas e a criatividade. A cada nível, o grau de dificuldade aumenta, de maneira que não haja sobrecarga de informações e o estudante possa praticar e generalizar as competências aprendidas nos níveis anteriores. O jogo, no momento atual, tem implementado integralmente o nível fácil em todas as fases. Além disso, temse o intuito de incluir requisitos de acessibilidade ao jogo, possibilitando que esse seja acessível para estudantes com Deficiência Intelectual.

A avaliação ocorreu com três estudantes do curso de Ciência da Computação, que puderam utilizar o jogo e respaldaram suas percepções por intermédio de um questionário on-line disponibilizado a eles. Com base nos feedbacks obtidos, realizaram-se melhorias no jogo. Ainda não foram realizados testes com o público-alvo, devido à pandemia COVID-19.

Como trabalhos futuros, pretende-se desenvolver novos níveis, implementar alterações de melhoria tanto no design quanto no funcionamento do jogo. Além disso, será realizada a avaliação do jogo com o público-alvo, as crianças, para obter informações a respeito de suas percepções e do comportamento do jogo no ambiente educacional.

\section{Agradecimentos}

Os autores agradecem o apoio do Conselho Nacional de Desenvolvimento Científico e Tecnológico (CNPq) 308395/2020-4, a FAPESC/CNPq No. 06/2016 projeto T.O. No.2017TR1755 - Ambientes Inteligentes Educacionais com Integração de Técnicas de Learning Analytics e de Gamificação, FAPESC/UDESC No. 04/2018 T.O No. 2019TR585 e FAPESC 27/2020 - Apoio à Infraestrutura para Grupos de Pesquisa da UDESC. 


\section{Referências}

BNCC (2018). Base nacional comum curricular: Educação é a base.

Brackmann, C. P. (2017). Desenvolvimento do Pensamento Computacional através de atividades desplugadas na Educação Básica. 2017. 226 f. PhD thesis, Universidade Federal do Rio Grande do Sul.

Cavadas, A., Fernandes, R. M., Motta, C., Marques, C., e Oliveira, C. (2019). Estratégia neuropedagógica computacional para promover o desenvolvimento de jovens em áreas de risco e vulnerabilidade social. In Anais do Workshop de Informática na Escola, volume 25, page 773 .

David, W., Alencar, L., Duarte, J., e de Sousa Pires, F. G. (2018). Tricô numérico: Um jogo para alfabetização matemática. In Anais dos Workshops do Congresso Brasileiro de Informática na Educação, volume 7, page 249.

Fisher, C. (2014). Designing games for children: Developmental, usability, and design considerations for making games for kids. CRC Press.

Gee, J. P. (2003). What video games have to teach us about learning and literacy. Computers in Entertainment (CIE), 1(1):20-20.

Gomes, T., Barreto, P., Lima, I. R. A., e Falcão, T. P. (2015). Avaliação de um jogo educativo para o desenvolvimento do pensamento computacional na educação infantil. In Anais dos Workshops do Congresso Brasileiro de Informática na Educação, volume 4, page 1349.

Grimes, R. H. e Hounsell, M. d. S. (2019). Sistema biomédico com jogo sério e dispositivo especial para reabilitação respiratória. Master's thesis, Universidade do Estado de Santa Catarina.

Henrique, M. S. (2016). Educatalog4re: um catálogo de requisitos para auxiliar o desenvolvimento softwares educacionais. Master's thesis, Universidade Federal de Pernambuco.

Koscianski, A. e Glitz, F. R. d. O. (2017). O pensamento computacional nos anos iniciais do ensino fundamental. Revista Novas Tecnologias na Educação. CINTED-UFRGS, $15(2)$.

Lima, G., Macena, J., de Souza, R. L., Pires, F., e Pessoa, M. (2019). Gramágica: um jogo de fantasia para aprendizagem de classificação silábica. In Anais dos Workshops do Congresso Brasileiro de Informática na Educação, volume 8, page 1350.

Nielsen, J. (1994). Usability engineering. Morgan Kaufmann.

Santos (2006). Jogos eletrônicos na educação: um estudo da proposta dos jogos estratégicos. Monografia (Bacharel em Ciência da Computação), UFS (Universidade federal de Sergipe), Sergipe, Brazil.

Savi, R. e Ulbricht, V. R. (2008). Jogos digitais educacionais: benefícios e desafios. RENOTE-Revista Novas Tecnologias na Educação, 6(1).

Schell, J. (2010). Arte de game design: o livro original. Crc Press.

von Wangenheim, C. G. e von Wangenheim, A. (2012). Ensinando computação com jogos. Bookess Editora, Florianópolis, SC, Brasil. 
Wing, J. M. (2006). Computational thinking. Communications of the ACM, 49(3):33-35.

Wing, J. M. (2011). Research notebook: Computational thinking-what and why. The link magazine, 6 . 